\title{
SLAYING 'THE NONSELECTIONIST THEORY' \\ OF LANGUAGE EVOLUTION
}

\author{
Rudolf P. Botha \\ University of Stellenbosch
}

1 'The nonselectionist theory'

In offering a justification for their selectionist account of the evolution of language, Steven Pinker and Paul Bloom (henceforth 'P\&B') argue that it compares favourably with certain nonadaptationist alternatives. Thus, they maintain that:

'... it is nonadaptationist accounts [rather than adaptationist ones --- R.P.B.] that are often in grave danger of vacuity. Specific adaptationist proposals may be unmotivated, but they are within the realm of biological and physical understanding, and often the problem is simply that we lack the evidence to determine which account within a set of alternative adaptive explanations is the correct one. Non-adaptationist accounts that merely suggest the possibility that there is some hitherto-unknown law of physics or constraint on form - a "law of eye-formation," to take a caricatured example - are, in contrast, empty and nonfalsifiable.' (Pinker and Bloom, 1990, p.711). ${ }^{\prime}$ 
And, having examined 'the motivations for the competing nonselectionist position', P\&B (1990, p.708) moreover 'suggest that [these motivations] have little to recommend them'.

These comparative judgements by $\mathrm{P} \& \mathrm{~B}$ could be highly pertinent to an assessment of the merits of their selectionist account and to those of selectionist accounts of language evolution in general. But are the shortcomings attributed by P\&B to competing nonselectionist accounts real shortcomings? And, more fundamentally, are these competitors real competitors or are they straw men, easy for $\mathrm{P} \& \mathrm{~B}$ to slay to make P\&B's selectionist account look better than it actually is? Pursuing these questions, I will argue that $\mathrm{P} \& \mathrm{~B}$ 's selectionist account cannot derive a significant measure of support from the shortcomings of the nonselectionist competitors considered by them. In arguing this point, I will examine a number of 'nonselectionist views' held by Noam Chomsky, by Massimo Piattelli-Palmarini and by Wendy Wilkins and Jenny Dumford/Jenny Wakefield on the evolution of language. I will argue that these nonselectionist views cannot be assigned the status of real alternatives to $\mathrm{P} \& \mathrm{~B}$ 's selectionist account of language evolution.

Before turning to the so-called nonselectionist views held by Chomsky and the other scholars referred to above, it is necessary to consider a matter of terminology. Note in this regard that $P \& B$ refer to these views as:

1 (a) 'the nonselectionist view' (Pinker and Bloom, 1990, p.708),

(b) 'the nonselectionist theory of language' (Pinker and Bloom, 1990, 
(c) 'the competing nonselectionist position' (Pinker and Bloom, 1990, pp.708, 711),

(d) 'nonadaptationist accounts' (Pinker and Bloom, 1990, p.711).

It will be shown below that the terminology adopted by $P \& B$ for referring to the views in question is in more than one way less than fortunate. First: these views differ from one another to such an extent that it is not useful to lump them together under the heading 'the nonselectionist view/theory/position'. Second: assigning to the collection of 'competing' views alternatively the status of a 'view', a 'theory', a 'position', an 'account' and an 'explanation' makes for an ill-directed form of comparative appraisal. Third: characterizing Chomsky's views in an unqualified way as 'nonselectionist' does not help to clarify these views.

\section{Chomsky's pluralism}

Over the past forty years, Chomsky has discussed a wide range of linguistic questions in a highly focused way. Questions about the evolution of language, however, have not been accorded such treatment by him. His views on language evolution are scattered over writings which primarily address other, non-evolutionary, matters. And these views do not add up to anything that would in a nontrivial sense constitute an account, an explanation or a theory of the evolution of language.

First, the function of an account or explanation of something is by its very nature

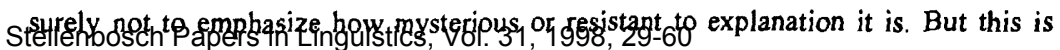
doi: $10.5774 / 31-0-56$ 
exactly what Chomsky has done when commenting on the evolution of language. He has even gone so far as to portray it as a phenomenon that has become more mysterious over the years. Thus, a quarter of a century ago, Chomsky asserted:

'In fact, the processes by which the human mind achieved its present stage of complexity and its particular form of innate organization are a total mystery, as much so as the analogous questions about the physical or mental organization of any other complex organism.' (Chomsky, 1972, p.97).

Recently, Chomsky has drawn certain 'conclusions' which look 'reasonable' to him and which, if correct,

'pose new mysteries to add to the ancient ones [shrouding the evolution of language --- R.P.B.].' (Chomsky, 1996b, p.30).

The 'conclusions' which compound the mystery of the evolution of language for Chomsky include the following:

2 (a) '... language is surprisingly "perfect" [in regard to design -.- R.P.B.]; satisfying in a near-optimal way some rather general conditions imposed at the interface [where language interacts with other components of the mind/brain --- R.P.B.]. (Chomsky, 1996b, p.30). ${ }^{2}$

(b) '... [in being surprisingly "perfect" - R.P.B.], language seems unlike Stellenbosch Papers in Ling doi: $10.5774 / 31-0-56$ 
messy solution to some class of problems, given the physical constraints and the materials that history and accident have made available'. (Chomsky, 1996b, p.30).

(c) '... [since --- R.P.B.] evolution is a tinkerer ..... and the results of its tinkering may not be what a skilled engineer would construct from scratch to satisfy existing conditions ..... language is rather special and unique [in regard to origin too --- R.P.B.]'. (Chomsky, 1996b, p.30).

If the function of an account, an explanation or a theory is to contribute to the understanding of phenomena, it is clear from the views quoted above that Chomsky cannot have been offering an account, an explanation or a theory of language evolution.

Second, it is not possible to offer an account, an explanation or a theory of language evolution without expressing precise factual claims about it. When considering what Chomsky has said over the years about the evolution of the mind/brain, language and other mental capacities, however, one is struck by the number of his assertions which are not expressed in a factual mode or which are so highly qualified that they lack precise factual import. The following cases are illustrative of this point [all emphases added]:

3 (a) 'In studying the evolution of mind, we cannot guess to what extent there are physically possible alternatives to, say, transformational generative grammar, for an organism meeting certain other physical Stellenbosch Papers in Linguistics, Vol. 31, 1998, 29-60 
conditions characteristic of humans. Conceivably, there are none - or very few - in which case talk about evolution of the language capacity is beside the point.' (Chomsky, 1972, pp.97-98).

(b) 'These skills [e.g., learning a grammar and recognizing faces -.R.P.B.] may well have arisen as a concomitant of structural properties of the brain that developed for other reasons. Suppose that there was selection for bigger brains, more cortical surface, hemispheric specialization for analytic processing or many other properties that can be imagined. The brain that evolved might well have all sorts of special properties that are not individually selected; there would be no miracle in this, but only the normal workings of evolution.' (Chomsky 1982b, p.321).

(c) 'In this regard [the evolution of infinite digital systems], speculations about natural selection are no more plausible than many others; perhaps these are simply emergent physical properties of a brain that reaches a certain level of complexity under the specific conditions of human evolution.' (Chomsky, 1988b, p.22 in MS).

(d) In some cases it seems that organs develop to serve one purpose and, when they have reached a certain form in the evolutionary process, became available for different purposes, at which point the processes of natural selection may refine them further for these purposes .. 
Possibly human mental capacities have in some cases evolved in a similar way.' (Chomsky, 1988a, p.167).

(e) 'It is likely that the evolution of human cortical structures was influenced by the early acquisition of a linguistic capacity, so that articulated language "not only permitted the evolution of culture, but has contributed in a decisive fashion to the physical evolution of man"; there is no paradox in supposing that "the linguistic capacity that reveals itself in the epigenetic development of the brain is now part of 'human nature'", itself intimately associated with other aspects of cognitive function which may in fact have evolved in a specific way by virtue of the early use of articulated language.' (Chomsky, 1971, pp. 10-11). ${ }^{3}$

(f) 'It might be that unknown physical laws apply in such a way [as to] afford the brains that evolved (under selection for size, particular kinds of complexity, etc.) the ability to deal with properties of the number system, continuity, abstract geometrical space, certain parts of natural science, and so on.' (Chomsky, 1982b, p.321).

(g) 'There is no reason to demand and little reason to suppose that genetically-determined properties invariably result from specific selection - consider the case of the capacity to deal with properties of the language system. They might, for example, arise from the 
regulatory mechanisms, or they might be concomitants to other properties that are selected, or they might result from mutation or genetic engineering ... ' (Chomsky, 1980, p.100).

In virtue of their speculative or highly qualified nature, the type of assertion made in 3(a) - (g) clearly cannot form part of a factual account of the evolution of language. Interestingly, Chomsky himself has more than once pointed out the futility of asking senseless questions or offering vacurous speculations about the evolution of the mind in general or language in particular:

4 (a) 'With no knowledge of the laws that determine the organization and structure of complex biological systems, it is just as senseless to ask what the "probability" is for the human mind to have reached its present state as it is to inquire into the "probability" that a particular physical theory [relating to neuron packing --- R.P.B.] will be devised.' (Chomsky, 1980, p.100).

(b) 'The vacuity of such speculation [about physically possible alternatives to transformational grammar --- R.P.B.], however, has no bearing one way or another on those aspects of the problem of mind that can be sensibly pursued.' (Chomsky, 1972, p.98).

Given Chomsky's emphasis on the mysterious nature of language evolution and the qualified way in which he has speculated about language evolution, it is not surprising that he has not claimed to have an account, an explanation or a theory of this Stellenbosch Papers in Linguistics, Vol. 31, 1998, 29-60 
phenomenon. ${ }^{4}$ This makes it even harder to maintain that P\&B's selectionist account of the evolution of language compares favourably with Chomsky's 'nonselectionist account' (see 1(b) above) or 'nonadaptationist account' (see 1(d) above). This, of course, is not to say that Chomsky's speculative views about the evolution of language are highly meritorious or that they are free of some or all of the flaws attributed to them by $P \& B$ and others. ${ }^{5}$

To conclude this section on Chomsky's views on language evolution, let us briefly consider the role he speculatively assigns to natural selection in language evolution. In this connection, various scholars have claimed that Chomsky does not accord any or any significant role to natural selection in the evolution of language. Consider, for example, the following statements by $\mathrm{P} \& \mathrm{~B}$ :

5 (a) '[Chomsky has] repeatedly suggested that language may not be the product of natural selection, but a side effect of other evolutionary forces such as an increase in overall brain size and constraints of as yet unknown laws of structure and growth ... ' (Pinker and Bloom, 1990, p.708).

(b) '[Chomsky has suggested] that the complexity of language cannot be explained through natural selection.' (Pinker and Bloom 1990, p.708).

(c) '[Chomsky] repeatedly urges us to consider "physical laws" as possible alternatives to natural selection.' (Pinker and Bloom 1970, p.720) 
In the BBS discussion, however, Otero rejects claims such as 5(a) - (c) by P\&B, contending that:

6 (a) 'I know of no evidence that Chomsky ever (let alone "repeatedly") suggested that "language may not be [in any respect] the product of natural selection", and P\&B offer none' (Otero, 1990, p.748). ${ }^{7}$

(b) 'Chomsky's view is then consistent with the thesis that language was shaped in some respects by natural selection'. (Otero, 1990, p.748).

But what is Chomsky's own reaction to the criticism that he has failed to accord natural selection any or any significant role in the evolution of language? Two recent responses of his are of some interest.

First, there is Chomsky's response to John Maynard Smith's (1995, p.41) characterization of Chomsky's view that 'In the case of such systems as language or wings, it is not easy even to imagine a course of selection that might have given rise to them' as 'completely baffling':

'If the ability to learn a language is innate, it is genetically programmed, and must have evolved. But Chomsky refuses to think about how this might have happened.' (Maynard Smith, 1995, p.48).

Rejecting Maynard Smith's reading of a specific 'phrase' used by him, Chomsky counters:

Stellenbosch Papers in Linguistics, Vol. 31, 1998, 29-60

doi: $10.5774 / 31-0-56$ 
'Smith cites only the last phrase quoted, misreading it as placing language and wings outside the scope of evolutionary theory - "baffling" no doubt, and exactly the opposite of what the passage unambiguously states ...' (Chomsky, 1996a, p.41).

Interestingly, Maynard Smith declares himself 'delighted' by this response, which he understands as follows:

'... Professor Chomsky agrees that the origin of language, like that of other complex organs, must ultimately be explained in Darwinian terms, as the result of natural selection.' (Maynard Smith, 1996, p.41).

Second, in a recent lecture, Chomsky invokes a distinction between two forms of Darwinism: 'ultra-Darwinism' and 'orthodox Darwinism'. ' 'Ultra-Darwinism' he rejects as both 'irrational' and 'incoherent.' ${ }^{9}$ It is 'irrational' in the sense that it attempts to explain (the evolution of) 'everything' or 'every property' in terms of natural selection. In this respect, Chomsky likens 'ultra-Darwinism' to creationism, which assumes a single cause, namely God, for whatever (property) is to be explained. 'UltraDarwinism', moreover, is 'incoherent', according to Chomsky since, unlike 'orthodox Darwinism', it does not assume that there is a physical channel (in which evolution has to take place). Chomsky considers Pinker and Bloom 'ultra-Darwinists', while he himself, it appears, subscribes to 'orthodox Darwinism'. ${ }^{10}$

But where, then, does Chomsky fit natural selection into the evolution of language? It would be consistent with various pronouncements of his to say that he provides, albeit Stellenbosch Papers in Linguistics, Vol. 31, 1998, 29-60

doi: $10.5774 / 31-0-56$ 
in a speculative way, for two basic phases in the evolution of language: a first in which language 'emerged' in an essentially mysterious way, and a second in which language was 'refined' or shaped by natural selection. Consider in this connection the following statements:

7 (a) '[An innate language faculty] poses a problem for the biologist, since, if true, it is an example of true "emergence" - the appearance of a qualitatively different phenomenon at a specific stage of complexity of organization.' (Chomsky, 1972, 70).

(b) '[Natural selection] can explain how you get a different distribution of qualities that are already present, but it does not say much about how new qualities can emerge.' (Chomsky, 1982a, p.23).

(c) 'In some cases it seems that organs develop to serve one purpose and, when they have reached a certain form in the evolutionary process, became available for different purposes, at which point the process of natural selection may refine them further for these purposes ... Possibly human mental capacities have in some cases evolved in a similar way.' (Chomsky, 1988a, p. 167).

In keeping with his view of the mysterious nature of language evolution, Chomsky has refrained from fleshing out his speculations about the (initial) 'emergence' of language and its (subsequent) 'refining' or shaping by natural selection: he has not

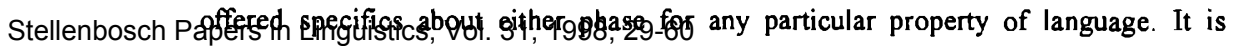
doi: $10.5774 / 31-0-56$ 
difficult to conclude more than that, by speculatively providing for a significant role for more than one evolutionary process or causal force, Chomsky seems to subscribe to a form of pluralism as far as the genesis of language is concerned.

\section{$3 \quad$ Piattelli-Palmarini's exaptationism}

Piattelli-Palmarini (1989) is more explicit than Chomsky about the role not played by natural selection and (resulting) adaptation in the evolution of language. Thus, he contends that:

'So far, none of the quite specific mechanisms, aptitudes and computational procedures posited by generative linguistics minimally lends itself to an adaptationist explanation. What is worse (from the standpoint of the strict adaptationist) is that, the more we understand them, the less plausible any adaptive explanation appears.' (Piattelli-Palmarini, 1989, p.19).

He goes on to assert that:

'The study of language has, in fact, disclosed many instances of specificity and gratuity in the design of all natural human languages, but hardly any instance of traits dictated by generic communicative efficiency or constraints dictated by the laws of pure logic.' (Piattelli-Palmarini, 1989, p.22). 
To illustrate these points, Piattelli-Palmarini $(1989$, p.23) refers to the projection principle and the principle of full interpretation. As formulated by him, the projection principle states that in every grammatically correct sentence of every natural language, 'each thematic role (a technical notion which subsumes and generalizes those of agent, object, instrument, event etc.) has to be discharged by one and only one admissible candidate'. And the principle of full interpretation states that 'no particle of language can be added to a sentence without being ipso facto interpreted by us'. In Piattelli-Palmarini's view, an abstractly conceivable system of communication could be based on totally different principles. He believes that there is nothing 'adaptive' or 'simple' about either the projection principle or the principle of full interpretation:

'Adaptationism cannot even begin to explain why the natural languages that we can acquire and use possess these central features and not very different ones.' (Piattelli-Palmarini, 1989, p.24). ${ }^{11}$

'Popular notions' such as 'general intelligence', 'problem-solving' and, notably, 'communicative function' are according to Piattelli-Palmarini (1989, p.26) 'totally useless' for understanding the origin and nature of human language. Going even further, he contends that:

'The Darwinian adaptationist picture not only fails to explain even the most central features of language and mind, but it forces on us intuitions that are highly misleading.' (Piattelli-Palmarini, 1989, p.26). 
Piattelli-Palmarini (1989, p.26) urges his readers to adopt an 'exaptationist picture' of the evolution of language, a 'picture' in which 'these constrictions and fallacies have no reason to apply'. This picture, he believes, would allow us

$\therefore$ at least to reconcile what has been independently discovered in the domain of language with a biologically credible story.' (Piattelli-Palmarini, 1989, p.26).

So, what does Piattelli-Palmarini's 'exaptationist picture' of the evolution of language look like? Here is the essence of his answer:

'In the new picture, what we state is that the innate, very specific and highly abstract structures governing language and cognition may also be seen as "spandrels", that is, biological traits that have become central to our whole existence, but which may well have originally arisen for some purely architectural or structural reason (perhaps overall brain size, or the sheer duplication of pre-existing modules), or as a by-product of evolutionary pressures driven by other functions (say, an increase in connectivity, or in submodularization).' (Piattelli-Palmarini, 1989, p.19). ${ }^{12}$

Exaptation, as characterized by Gould and $\mathrm{Vrba}_{\mathrm{r}}{ }^{13}$ is an indirect, serendipitous process by which traits (or genes) acquire some adaptive value - which they did not have before - because of a change in the environment or in the mode of life, or because of new behavioural strategies that are made possible by the appearance of these traits. ${ }^{14}$ 
The idea of exaptation forms in Piattelli-Palmarini's view part of a 'new' and 'better' theory of evolution which says that

'full-blown evolutionary novelty can also suddenly arise, so to speak, for no reason, because novelty caused by sheer proximity between genes is not governed by function and it, therefore, eludes strict adaptationism.' (PiattelliPalmarini, 1989, p.8). ${ }^{15}$

While Piattelli-Palmarini is less guarded than Chomsky about the nature of the evolutionary mechanisms that might have played a role in the evolution of language, the 'exaptationist picture' of language evolution he draws cannot be considered a theory offering an explanation or an account of this evolution. First, this 'picture' is deficient in being painted in the wrong modality in regard to what it asserts about the evolution of language. Strongly qualified with the aid of expressions such as 'may be' and 'may well have', these assertions are of a speculative sort not amenable to refutation, as is evidenced by the following examples [emphases added]:

8 (a) '... it is now important to show that they [i.e., language and cognition -- R.P.B.] may well have arisen from totally extra-adaptive mechanisms.' (Piattelli-Palmarini, 1989, p.6).

(b) 'In the new picture, what we state is that the innate, very specific and highly abstract structures governing language and cognition may also be seen as "spandrels", that is, biological traits that have become 
arisen for some purely architectural or structural reason (perhaps overall brain size, or the sheer duplication of pre-existing modules), or as a by-product of evolutionary pressures driven by other functions (say, an increase in connectivity, or in submodularization).' (PiattelliPalmarini 1989, p. 19).

Second, in being extremely general, Piattelli-Palmarini's 'exaptationist picture' falls short of what an explanatory account of the evolution of language should be. That is, this 'picture' offers no specifics about how particular traits of language actually evolved. Piattelli-Palmarini seems to be aware of this shortcoming when he says the following about his views on the so-called extra-adaptive mechanisms by which language supposedly evolved:

'This does not bring us (for the time being) any closer to a detailed reconstruction of the evolutionary origins of language and cognition, but it provides, for the first time, a plausible biological "background" explanation of the way language and cognition actually are.' (Piattelli-Palmarini, 1989, p.6).

A 'picture' of the evolution of language offering little more than highly qualified generalities is of course open to P\&B's (1990:711) criticism of 'vacuity'. The merit of Piattelli-Palmarini's work on the evolution of language, accordingly, is not to be found in the 'exaptationist picture' proposed by him. It lies rather in his discussion of the threat posed by functionless traits of language to selectionist accounts of the kind proposed by P\&B. ${ }^{16}$ To conclude: since Piattelli-Palmarini's 'exaptationist picture' of

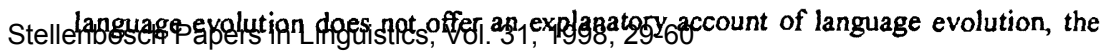
doi: $10.5774 / 31-0-56$ 
merit of P\&B's selectionist account is not actually boosted by the fact that it compares favourably with this 'picture'.

\section{Wilkins and Wakefield's reappropriationism}

In a BBS target article, Wilkins and Wakefield (henceforth W\&W) offer 'an account of the origins of language' which they (1995, p.205) consider to be an alternative to P\&B's account. ${ }^{17}$ Unlike that of P\&B, the account offered by W\&W is not

'... based on an apparently self-evident, and therefore unexamined truth: language is the product of natural selection via adaptation, and hence has evolved somehow from the communication $\operatorname{system}(s)$ of our ancestors.' (Wilkins and Wakefield, 1995, p.205).

Though W\&W (1995, p.205) judge P\&B's account to be the 'most thorough ... and sophisticated' selectionist account to have been offered recently, they reject it because

'... it suggests the naive view that language (as the superlative human communication device) is, and always has been, adaptive, and thus would have been the subject of selective pressures.' (Wilkins and Wakefield, 1995, p.205).

But what is the thrust of W\&W's own account? And does it offer a real alternative to Stellenbosch Papers in Linguistics, Vol. 31 , These are the general questions which I will pursue doi: $10.5774 / 31-0-56$ 
below. In their target article, W\&W $(1995$, p.161) address the question of the 'evolutionary emergence of language' by presenting 'a plausible evolutionary scenario for the emergence of the neural preconditions for language in the homonid lineage'. Language is considered by them $(1995$, p.206) to be a formal grammatical system that exists as a biologically determined 'language capacity', 'linguistic capacity' or 'linguistic ability'. The basic claims of their account of the evolutionary origin of language are to be found in the following passage:

'The neuroanatomical structures that underlie linguistic ability, we will argue, arose in human taxa as a direct result of evolutionary reappropriation ... . They evolved to the state at which they were available so that incipient linguistic capacity could emerge by gradual, adaptive changes in brain organization. These changes were the result, in the hominid line, of natural selection for other behaviors that require specific, highly sophisticated neural processing mechanisms. These neuroanatomical structures were not adaptations originally serving communicative functions, however. Our investigation of the origins of language is concerned specifically with the reappropriative basis of these structures rather than subsequent adaptive mechanisms that may have shaped language as a communicative device.' (Wilkins and Wakefield, 1995, p.162).

The term 'reappropriation' is used by W\&W $(1995, \mathrm{p} .162)$ in the sense of 'the means by which a structure or function in the repertoire of a species reaches an evolutionary state that is compatible with, and facilitates, a new function'. Reappropriation is Stellensidered by W\&W to be the same phengmenon that was called 'preadaptation' by 
Darwin. They do not wish to use the latter term, however, since it has developed 'an unintended connotation of premeditation'.

In outline, the evolutionary scenario presented by W\&W is made up of the following (composite) claims:

9 (a) Through adaptive changes, there was in pleistocene primate lineages a paired expansion of frontal and parietal neocortex associated with manual manipulation and throwing behaviours. (Wilkins and Wakefield, 1995, pp.161, 172).

(b) This expansion resulted in the appearance of two language-related cortical areas: Broca's area and the POT, a configurationally unique junction of the parietal, occipital and temporal lobes of the brain indicative of Wernicke's area. (Wilkins and Wakefield, 1995, pp.161167).

(c) 'By virtue of the POT, human sensory input is highly processed in the association cortex and loses its modality-specific character; by virtue of the influence of Broca's area on the POT, the amodal representations are subject to hierarchical structuring.' (Wilkins and Wakefield, 1995, p. 175).

(d) The interaction of the POT and Broca's area yields cognitive structure

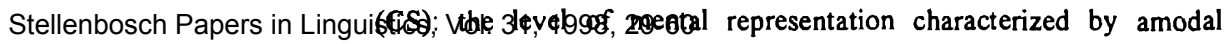
doi: $10.5774 / 31-0-56$ 
hierarchical structuring at which linguistic, sensory and motor information are compatible. (Wilkins and Wakefield, 1995, p. 175).

(e) CS and its biological basis give language its referential character. (Wilkins and Wakefield, 1995, p. 175). ${ }^{18}$

(f) CS, however, is not part of the linguistic system per se but is related to it through a set of correspondence rules. (Wilkins and Wakefield, 1995, p. 175).

W\&W (1995, p. 177) 'reiterate' that their account of the emergence of the POT and Broca's area does not 'depend on selectional pressures for strictly linguistic ability in the earliest hominids'. They consider selectional pressures for improved eye-hand coordination and manipulative capacities to be clearly established in the fossil and archaeological records. And they emphasize that:

'[Their] account relies on the reappropriation of the expanded, or appended, neural modules associated with these abilities. The cognitive products that were made possible by the reappropriation of these structures, once established, may themselves have been highly adaptive and available for selection.' (Wilkins and Wakefield, 1995, p.177).

W\&W are strangely ambivalent about what their reappropriationist account is an account of. On the one hand they (1995, p.205) portray it as 'an account of the origins of language'. On the other hand, they $(1995$, p. 206$)$ describe it as an account of 'the Stellenbosch Papers in Linguistics, Vol. 31, 1998, 29-60

doi: $10.5774 / 31-0-56$ 
neural preconditions for language', an account of the emergence of the POT and Broca's area, whose interaction 'yields' CS. About CS they observe that:

'... having CS is not the same as having language ... In fact, if the theory of grammar that we are assuming is correct, CS is not itself even a part of grammar.' (Wilkins and Wakefield, 1995, p.177).

W\&W, moreover, caution their readers:

'It also falls outside the scope of the target article to speculate on how language evolved once the emergent capacity and CS came into existence.' (Wilkins and Wakefield, 1995, p.97).

And:

'We make no substantive claim here about how modern syntax and phonology might have evolved (although the hierarchical ordering, necessary to these components, would have been available).' (Wilkins and Wakefield, 1995, p.179).

It is hard to see, then, how W\&W $(1995$, p.205) could view their reappropriationist account as an 'alternative approach' to P\&B's selectionist account. The latter is intended to be an account of the phase of language evolution about which W\&W (profess that they) have nothing to say, a phase characterized by P\&B (1990, p.765) as 
not that of 'the appearance of a structure in its initial form', but that of 'the elaboration and complication [of a structure] that leads to its fulfilling its current function'.

It is accordingly not strange that various BBS commentators do not consider W\&W's reappropriationist account to be an account of the evolution of language. In Derek Bickerton's (1995, p. 182) phrasing 'they do not state what else ... was required for the full flowering of language', a point made in a slightly different way by Hurford and Kirby $(1995, \mathrm{pp} .193,194)$ as well. It is instructive to consider W\&W's response to these peer criticisms [emphases added]:

'... what happened next [i.e., after the reappropriation had taken place -.R.P.B.] might well have been adaptation toward complexity ... Communicative interaction might be the necessary ingredient for the development of the complexity that characterizes all components of human language, including phonology, syntax and morphology.' (Wilkins and Wakefield, 1995, p.218).

What W\&W claim here about the evolution of language is so general and speculative that P\&B's label of 'vacuity' can be justifiably attached to it as well. W\&W, in fact, seem to think that it is not possible to bring empirical evidence to bear on such speculations:

'... if the reappropriated structures were later modified through natural selection, there is simply no evidence about the course the process took.' (Wilkins and Wakefield, 1995, p.218). 
And, stressing the 'tremendous lack of evidence' in the final paragraph of their response, W\&W conclude that

'... much further speculation on such evolution will have to be done within the confines of logic and debate in the relevant disciplines.' (Wilkins and Wakefield, 1995, p.219).

In sum: W\&W's reappropriationist account may or may not offer 'a plausible evolutionary scenario for the emergence of the neural preconditions for language in the homonid lineage'. ${ }^{19}$ It is clearly, however, not an account of the evolution of language as such and hence not comparable with P\&B's selectionist account. Whatever the flaws or merits of W\&W's reappropriationist account may be, these cannot be brought to bear, in either a positive or a negative way, on the adequacy of P\&B's selectionist account.

\section{$5 \quad$ A straw man}

The nonselectionist theory or account of language evolution has indeed turned out to be a straw man. There are alternative nonselectionist views which should not be collapsed into a single one. Not all of these views, moreover, are as nonselectionist as they may appear at first blush. And none of those referred to by P\&B satisfies the basic criteria for a theory or an explanatory account. ${ }^{20}$

Acknowledgement - I would like to thank Jules Coxhill and Walter Winckler for their

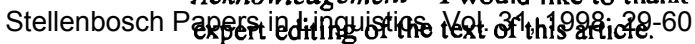




\section{NOTES}

1 P\&B state the gist of their selectionist account of the evolution of language as follows in a 1990 target article in Behavioral and Brain Sciences (henceforth 'BBS'):

'... human language, like other specialized biological systems, evolved by natural selection. Our conclusion is based on two facts that we would think would be entirely uncontroversial: Language shows signs of complex design for the communication of propositional structures, and the only explanation for the origin of organs with complex design is the process of natural selection.' (Pinker and Bloom 1990, p. 726).

For a critical appraisal of P\&B's selectionist account of language evolution and of other selectionist accounts of the same type, see Botha (1997a, 1997b, 1998a, 1998b).

2 See also Chomsky (1995b, p.32) for the view that language is 'almost a perfect solution to these external conditions'. For technical particulars of the context in which Chomsky poses the question 'How perfect is language?', see Chomsky (1995a, pp.1-11, 219-225). Jackendoff (1997, p.20), interestingly, disagrees with Chomsky on how perfect language is.

3 The stretches in double quotation marks are from Monod (1970, pp. 150-151).

4 This is in keeping with the highly constrained way in which Chomsky (1995b, p.32) has used the notion of a 'theory (of something)'.

5 P\&B (1990) do not consider in an explicit and systematic way the question of the conditions --- ontological, logical, epistemological, substantively linguistic, etc. - which a set of claims has to meet in order to qualify as an Stellenbosch Paper's in Linguistics, Vol. 31, 1998, 29-60 
account, explanation or theory of the evolution of language. For some thoughts on the conditions which a research programme focusing on the evolution of communication should meet, see Hauser (1996, p.70).

6 The idea that Chomsky does not assign natural selection any or any significant role in the evolution of language has been expressed by other scholars as well, including Dennett (1995a, p.389; 1995b, p.122), Maynard Smith (1995, p.290), and Hauser (1996, pp.36, 50).

7 P\&B's response to these statements by Otero reads as follows: 'Otero hints that we may have misrepresented Chomsky's views, which are "consistent with the thesis that language was shaped in some respect by natural selection." This is somewhat misleading. Chomsky's skeptical remarks are literally stated of "language" (of "grammar"), not "certain aspects of language" (see sects. 1 and 4.2 of the target article). More important, the issue is not whether there is at least one aspect of language that was shaped by natural selection, because this weak statement encompasses a vast range of positions that are very much worth distinguishing. Although it is literally correct to say that "the eye was shaped in some respects by natural selection," it is almost a joke, as it gives us no way of distinguishing the eye from a morphological epiphenomenon like the chin, some of whose aspects, no doubt, were also shaped by natural selection. It is exactly those aspects of the eye that we are most interested in as physiologists and anatomists that are shaped by natural selection: the aspects that allow it to be used as an organ for sight. The question is whether this is also true of language, namely, whether it, like the eye, is an adaptation.' (Pinker and Bloom, 1990, p.768). 
8 This lecture, entitled 'The state of the minimalist art' (= Chomsky 1997), was presented at the University of Cape Town on 29 May 1997.

9 Eldredge (1995) uses the term 'ultra-Darwinists' to refer to scholars who share a conviction that natural selection regulates everything of any importance in evolution, and that adaptation emerges as a universal result and ultimate test of selection's ubiquity. For this point, see Gould (1997a, p. 34).

10 In their target article, P\&B (1990, p.720) do assert that 'it is certainly true that natural selection cannot explain all aspects of the evolution of language', but without elaborating on this assertion. Recently, in a polemical exchange with Pinker, Gould (1997b, pp.57-58) has argued that Pinker is so committed to 'adaptationist logic' that he is unable to 'conceptualize the altemative properly' (p.57); and that Pinker's 'viewpoint only admits arguments about adaptation into the domain of "evolutionary reasoning" ..' (p.58). Gould (1997a, p.34), incidentally, refers to the form of Darwinism that assigns to natural selection the status of the sole cause of evolution as 'Darwinian fundamentalism'.

11 For a response --- central to which is the notion of 'built-in arbitrariness' --- see P\&B (1990, p.718).

12 See Gould and Lewontin (1979) for the introduction of the architectural concept of 'spandrel' for the purpose of characterizing a certain kind of biological trait. See Gould (1997b, pp.57-58) for a recent attempt to clear up some of the confusion that has arisen about the nature of 'biological spandrels'.

13 Piattelli-Palmarini (1989, p. 10) refers to Gould and Vrba (1982) and Vrba and Gould (1986) for this characterization of exaptation.

14 See also Bryant (1995, p. 184) for this concept of 'exaptation'. 
15 This 'new' and 'better' theory of evolution is called 'neo-neo-Darwinism' by Piattelli-Palmarini (1989, p.8).

16 This discussion is marred, however, by the fact that, like P\&B, PiattelliPalmarini does not clearly distinguish between functionlessness, nonoptimality and arbitrariness. For this distinction, see Botha (1997b, pp.324-329).

17 Some of the ideas central to W\&W's account were presented in outline by Wilkins and Dumford (1990) in their BBS commentary on P\&B's selectionist account.

18 'Conceptual structure' is a fundamental concept of Jackendoff's (1983) theory of semantics.

19 The open peer commentary on W\&W's target article is, as a whole, rather negative, so negative in fact that W\&W $(1995$, p.205) have found it necessary to remark in their response: 'We are not telling the story that our audience is expecting to hear; nor, in large part, is our audience hearing the story we are telling'.

20 The fact that there are no real alternatives to P\&B's selectionist account of language evolution should be treated with caution. It indicates neither that this account is correct nor that the correct account will turn out to be a selectionist one. For a summary of the various flaws of P\&B's selectionist account, see Botha (1998b, section 5). 


\section{REFERENCES}

Allen, C. and Bekoff, M. (1995) Biological function, adaptation and natural design. Philosophy of Science 62, 609-622.

Bickerton, D. (1995) Finding the true place of Homo habilis in language evolution. Behavioral and Brain Sciences 18, 182-183.

Botha, R.P. (1997a) Neo-Darwinian accounts of the evolution of language: 1 Questions about their explanatory focus. Language and Communication 17, 246-267.

Botha, R.P. (1997b) Neo-Darwinian accounts of the evolution of language: 2 Questions about complex design. Language and Communication 17, 319-340.

Botha, R.P. (1998a) Neo-Darwinian accounts of the evolution of language. 3 Questions about their evidential bases, logic and rhetoric. Language and Communication 18, 17-46.

Botha, R.P. (1998b) Neo-Darwinian accounts of the evolution of language. 4 Questions about their comparative merit. Language and Communication 18.

Bryant, D.J. (1995) Is preadaptation for language a necessary assumption? Behavioral and Brain Sciences 18, 183-184.

Chomsky, N. (1971) Problems of Knowledge and Freedom. The Russell Lectures. Pantheon: New York.

Chomsky, N. (1972) Language and Mind. Enlarged Edition. Harcourt Brace Jovanovich: New York.

Chomsky, N. (1980) Rules and Representations. Columbia University Press: New York. 
Chomsky, N. (1982a) The Generative Enterprise: A Discussion with Riny Huybregts and Henk van Riemsdijk. Foris: Dordrecht.

Chomsky, N. (1982b). Discussion of Putnam's comments. In Language and Learning: The Debate between Jean Piaget and Noam Chomsky, ed. M. PiattelliPalmarini, pp.310-324. Routledge \& Kegan Paul: London.

Chomsky, N. (1988a) Language and Problems of Knowledge. The Managua Lectures. MIT Press: Cambridge, MA.

Chomsky, N. (1988b) Prospects for the study of language and mind. Paper presented at the conference on Linguistics and Cognitive Science: Problems and Mysteries, Israel, April 1988. [Published in The Chomskyan Turn, ed. A. Kasher, pp.26-53. Blackwell: Oxford. 1991.].

Chomsky, N. (1995a) The Minimalist Program. MIT Press: Cambridge, MA.

Chomsky, N. (1995b) Language is the perfect solution! Interview with L. Cheng and R. Sybesma. Glot International 1, pp. 1, 31-34.

Chomsky, N. (1996a) Language and evolution. Letter to The New York Review of Books, February 1, 1996, p.41.

Chomsky, N. (1996b). Powers and Prospects. Reflections on Human Nature and Social Order. South End Press: Boston.

Chomsky, N. (1997) The state of the minimalist art. Lecture presented at the University of Cape Town, 29 May 1997.

Dennett, D.C. (1995a) Darwin's Dangerous Idea. Evolution and the Meanings of Life. Simon and Schuster: New York.

Dennett, D.C. (1995b) Interview with Omni. Omni 17, 119-124.

Eldredge, N. (1995) Reinventing Darwin: The Great Debate at the High Table of Stellenbosch Papers in Evolutionary Theory. New York: John Wiley. 
Gould, S.J. (1997a) Darwinian fundamentalism. The New York Review of Books, June 12, 1997, pp.34-37.

Gould, S.J. (1997b) Letter to The New York Review of Books, October 9, 1997, pp.5658.

Gould, S.J. and Lewontin, R.C. (1979) The spandrels of San Marco and the Panglossian paradigm: A critique of the adaptationist programme. Proceedings of the Royal Society of London 205, 281-288.

Gould, S.J. and Vrba, E.S. (1982) Exaptation - a missing term in the science of form. Paleobiology 8, 4-15.

Hauser, M.D. (1996) The Evolution of Communication. MTT Press: Cambridge, MA. Hurford, J.R. and Kirby, S. (1995) Neural preconditions for proto-language. Behavioral and Brain Sciences 18, 193-194.

Jackendoff, R.S. (1983) Semantics and Cognition. MIT Press: Cambridge, MA.

Jackendoff, R.S. (1997) The Architecture of the Language Faculty. MTT Press: Cambridge, MA.

Maynard Smith, J. (1995) Genes, memes and minds. The New York Review of Books, November 30, 1995, pp.46-48.

Maynard Smith, J. (1996) Letter to The New York Review of Books, February 1, 1996, p.41.

Monod, J. (1970) Le hasard et le necessité. Seuil: Paris. American Edition (1971) Chance and Necessity. Alfred A. Knopf: New York.

Otero, C.P. (1990) The emergence of homo loquens and the laws of physics. Behavioral and Brain Sciences 13, 747-750.

Piattelli-Palmarini, M. (1989) Evolution, selection, and cognition: From "learning" to parameter setting in biology and the study of language. Cognition 31, 1-44. Stellenbosch Papers in Linguistics, Vol. 31, 1998, 29-60 doi: 10.5774/31-0-56 
Pinker, S. and Bloom, P. (1990) Natural language and natural selection. Behavioral and Brain Sciences 13, 707-727, 765-784.

Vrba, E.S. and Gould, S.J. 1986. The hierarchical expansion of sorting and selection: Sorting and selection cannot be equated. Paleobiology 12, 217-228.

Wilkins, W. and Dumford, J. (1990) In defense of exaptation. Behavioral and Brain Sciences 13, 763-764.

Wilkins, W. and Wakefield, J. (1995) Brain evolution and neurolinguistic conditions. Behavioral and Brain Sciences 18, 161-182, 205-226. 